\title{
Voice Leading Among Pitch-Class Sets: Revisiting Allen Forte's Genera
}

\author{
Paulo de Tarso Salles \\ University of São Paulo (USP) \\ ptsalles@usp.br \\ Orcid: 0000-0001-7939-4521
}

DOI: $10.46926 /$ musmat.2020v4n2.66-79

\begin{abstract}
The theory of PC-set class genera by Allen Forte [5] was an important contribution to the understanding of similarity relations among $P C$ sets within the tempered system. The growing interaction between the universes of PC-sets and transformational theories has explored the space between sets of the same or distinct cardinality, by means of voice-leading procedures. This paper intends to demonstrate Forte's method along with proposals by other authors like Morris [8], Parks [10], [9], [1], Straus [16], [15] Cohn [3], and Coelho de Souza [2]. Some analysis demonstrates such operations in passages picked from Heitor Villa-Lobos's works, like the Seventh String Quartet and the First Symphony.
\end{abstract}

Keywords: Genera. Voice leading. Similarity. Cardinality. Villa-Lobos.

\section{INTRODUCTION}

\begin{abstract}
llen Forte's article, "Pitch-Class Set Genera and the Origins of Harmonic Species" [5], is a A development of his previous theory on complexes of pitch-class sets [6, pp. 93-178]. Both are linked to a research field dealing with harmonic organization within the tempered system in the twentieth-century music, but its unfolding has taken different paths.).

Genera theory, as advanced by Allen Forte [5], proposes a kind of Darwinian parody on "harmonic species" built upon the smaller units, the trichords, and their division into "families". These families are Forte's idea to set a large-scale scheme of harmonic organization, displaying their homogeneity in post-tonal music contexts. In order to achieve a maximum coherence gathering those small units in increasingly large pc-sets, Forte adopted a system grounded on the interval vector similarity and inclusion among pc-sets.

Despite its cleverness, the theory of Genera presents some problems, whose solution is hard to find, maybe it's impossible. The most striking point is the inconsistence between what is told by similarity and inclusion against our perception. For instance, there is a considerable gap between what is not assigned as "tonal" according Forte's criteria and the real world of tonal music. Anyway, many other models have appeared with a similar end, like Parks [10], [9], Morris [8], Straus [16], [15], [14], Tymoczko [17], Cohn [3], and Coelho de Souza [2], among others.
\end{abstract}

Received: July 20th, 2020

Approved: October 13th, 2020 
I have no ambition to design a model of my own. My intention is just to revisit some aspects of Forte's theory, along with some studies on voice leading developed in the last three decades. The fusion between the static model - proposed by Forte from the pc-sets and their interval vectors with the dynamic model provided by transformational theory - based on voice leading - seems to be an interesting analytical approach to understand post-tonal harmony in some contexts. To fulfill this goal, I employ concepts often applied to art music in the first half of the twentieth century, such as cardinality change ([1], [15]) and voice leading ([8], [4], [16], [15], [2]). Thus, I intend to find a balance between theoretical consistence and perceptual data. However, the scope of this paper is concerned with some analytical insights, leaving a more comprehensive theory for a later time.

Villa-Lobos's music, with its complex layers of expanded tonal chords and lack of consistent functional progressions, offers an ideal opportunity to test the hypothesis on "harmonic species" and the transformational processes among them, like an enlarged concept of modulation. My methodology starts from the analyses of musical samples with transitional function between two well-defined tonal centers; chords and melody inside these passages are labeled and classified according to Forte's genera; it is followed by a study of the voice leading observed within the implied harmonic species.

\section{Forte's Genera Theory}

According to Forte, there are twelve genera, divided into four "simple" ones (based on a single trichord) and eight "complex" ones, which comes from two trichords sharing similar properties (Table 1).

Table 1: Forte's twelve Genera (author's conception, after [5])

\begin{tabular}{cccc}
\hline \hline Supra-Genus & Genus & Type & Trichord \\
\hline \multirow{2}{*}{ I } & G1 & Atonal & $3-5$ \\
& G2 & Whole tone & $3-8$ \\
& G3 & Diminished & $3-10$ \\
\hline & G4 & Augmented & $3-12$ \\
\hline II & G5 & Chroma & $3-1$ \& 3-2 \\
& G6 & Semi-Chroma & $3-2$ \& 3-3 \\
\hline & G7 & Chroma-Dia & $3-2$ \& 3-7 \\
\hline \multirow{3}{*}{ III } & G8 & Atonal & $3-3$ \& 3-4 \\
& G9 & Atonal-Tonal & $3-3$ \& 3-11 \\
& G10 & Atonal-Tonal & $3-4$ \& 3-11 \\
\hline IV & G11 & Dia & $3-7$ \& 3-9 \\
& G12 & Tonal & $3-7$ \& 3-11 \\
\hline
\end{tabular}

The Genera - except for G4 and G7 - are grouped into "Supra-Genera" in the following fashion: G1 + G2 + G3 = Supra-Genus I; G5 + G6 = Supra-Genus II; G8 + G9 + G10 = Supra-Genus III; and G11 + G12 = Supra-Genus IV. ${ }^{1}$

\footnotetext{
${ }^{1}$ Forte gathers genera into the supra genera, according to their common interval classes (ic) shared by their progenitor trichords. So, (012), (013), and (014) share ic 1 (half-tone), being grouped in Supra II. Supra I shares ic 6 (tritone); Supra III shares ic 4 , and Supra IV shares ic 5.
} 


\section{A VIEWING FROM GENUS 4: SOME PROPERTIES}

Forte sought to limit the number of supersets looking for the maximum consistence among their members, down to the basic trichords (progenitors). Thus, he eliminates all pc-sets whose complement is not a superset.

In Figure 1, Genus 4 is organized as a graph containing the 22 sets obtained from the augmented trichord (048), excluding those 11 ones with cardinality higher than 6. My graph has some additional features such as: the change of cardinality through SPLIT; and arrows indicating parsimonious movements between pc-sets. Straus [15, p. 56; 72] idealized a similar graph, displaying the offset from a chosen pc-set.

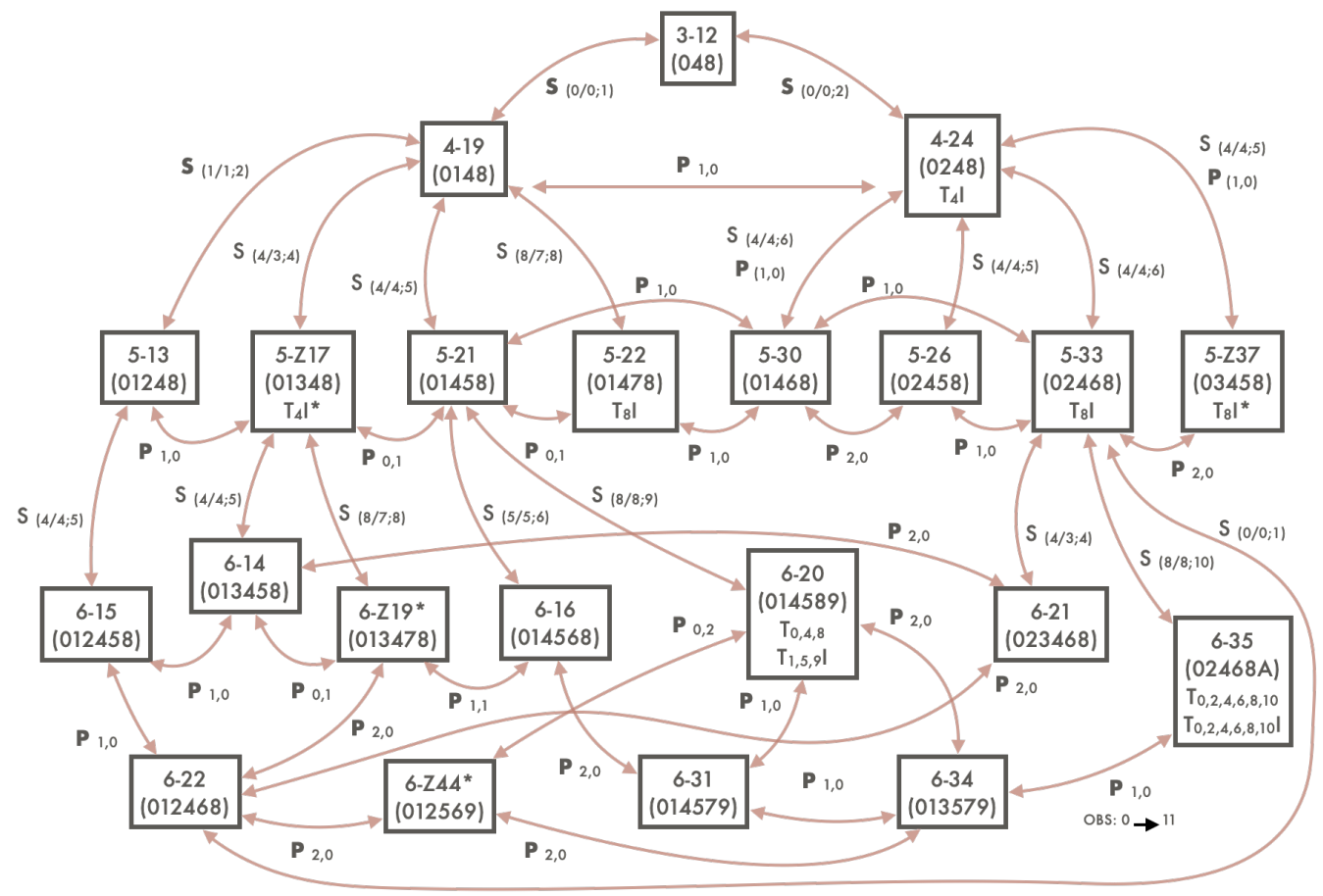

Figure 1: Genus 4, starting from (048) (author's conception. Made after [5], [1], [4], and [16]).

From the voice leading's graph on Genus 4, comes up the idea of generating a model of voice-leading zones, according to Richard Cohn's model [3, p. 102-4]. That circular representation reveals some curious properties due to the sum of pc-classes (Figure 2). All the $33 \mathrm{pc}$-sets belonging to Genus 4 are present, this time; pc-sets with cardinality 7, 8, and 9 have sums related with their complements in the following fashion:

a Pc-sets with cardinal 7 have " $\mathrm{n}-1$ " sum compared with cardinal 5 . The only exception is 7-z37 (sum n - 4), whose sum matches its z-related pair, 5-z17.

b Pc-sets with cardinal 8 have " $m-2$ " sum, compared to the " $m$ " sum of cardinal 4 .

c Pc-set 9-12 has "p - 3" sum against "p" sum of its progenitor, 3-12.

$\mathrm{d}$ The z-related hexachords 6-z19 and 6-z44 have the same sum.

The voice-leading zone with sum 10 is empty; on the other hand, the higher number of pc-sets with the same sum is on $6,7,8$, and 11 voice-leading zones. The possible meaning of these data 
could be verified through similar graphs for all remaining Genera, a task beyond the scope of this work.

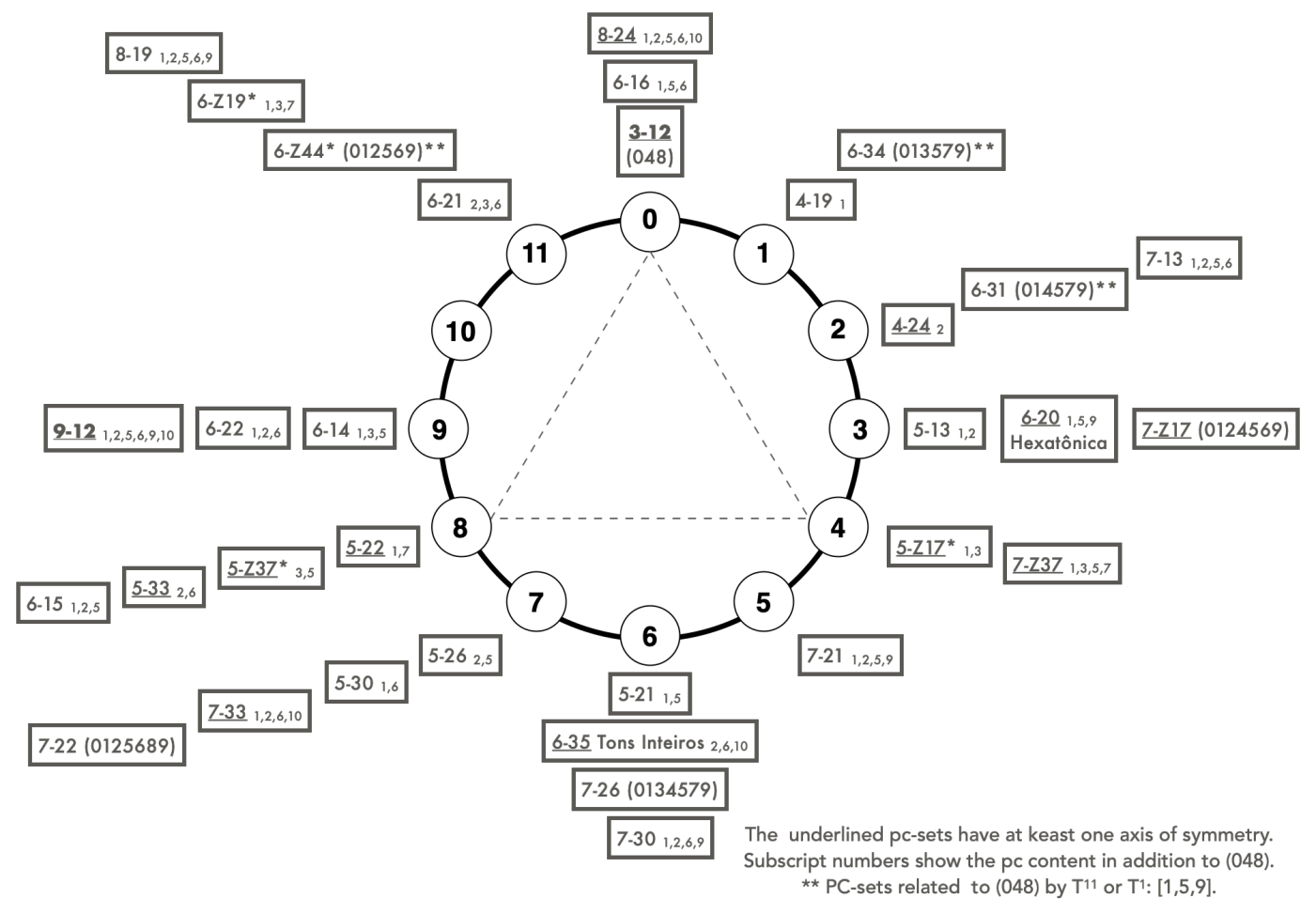

Figure 2: Genus 4 set over the voice-leading zones (author's conception. Made after [5] and [3]).

\section{IDENTIFYING HARMONIC GENERA AND ITS TRANSFORMATIONS IN THE MUSIC OF VILlA-LoBos}

Villa-Lobos's music is sometimes dismissed as "chaotic" because it wanders erratically between the triadic and non-triadic universes and because it oscillates between the banal and the genius. ${ }^{2}$ When examining his music more closely, we see that this is not necessarily true - at least in relation to "chaos" - nor does it seem relevant to establish value judgments based on subjective concepts such as "banal" or "genius". The composer is quite concerned with his harmonic materials, although he never discloses his actual processes of tonal organization. In my study on his string quartets [12] I find a correlation between form and tonality, anchored on cadences whose formal function resembles the Classical style. Of course, Villa-Lobos's harmony is completely different; in his peculiar treatment of the dissonance, interval symmetry takes the role of traditional consonance. ${ }^{3}$ Besides, the composer sets stable thematic areas in opposition to transitional or developmental areas. Thus, it seems possible to sketch a principle of tonal directionality in Villa-Lobosian music, employing genera of pc-sets in association with voice-leading mapping.

Villa-Lobos's Seventh String Quartet (1942) is a piece of music filled with neoclassical features as thematic areas in opposition to transitional or developmental sections, highlighted by textural

\footnotetext{
${ }^{2}$ Lisa Peppercorn claims that "is impossible to deal with all his work [...] because of their very uneven quality - works containing music which is at times banal, as well as music which has the stamp of genius" [11, p. 106]

${ }^{3}$ For a detailed study on Villa-Lobos's cadences in his string quartets, see [12, pp. 156-182].
} 
changes. I start with the segmentation of melodic and harmonic elements starting from the primary theme, passing through the transition, and reaching the subordinated second group of themes (Figure 3). The exposition of the first theme is a sequential progression in descending fifths, and its main motif is the diatonic "minor" tetrachord (0135), FN 4-11; during the transition, the minor chord with minor seventh (FN 4-26) is recurrent, making parallel movements along with the thematic statements.

Despite Forte's careful criteria, is somewhat disturbing to find that (0135) does not belong to Genus 12 (Dia-Tonal), but to Genus 7 (Chroma-Dia). Surprisingly, a typical diatonic tetrachord ${ }^{4}$ is labeled as a sort of mixture between chromatic and diatonic species; Forte's explanation is on the progenitor (025), shared by Genus 7 and Genus 12. Nevertheless, as most of its members are designated as primary members of Genus 12 , the passage has considerable harmonic consistency. ${ }^{5}$

The recomposition process -- in which the thematic materials presented in the exposition are resumed in the recapitulation - has some interesting features, which reveals how meticulous Villa-Lobos could be, concerning his melodic-harmonic materials (Table 2). ${ }^{6}$ At first sight, the sequential progression of the first theme seems to be overruled by a "major" diatonic tetrachord (C-D-E-F instead of the expected G-Ab-Bb-C) that pops up at mm. 154-156, demonstrating his awareness to the inversional property between these pc-sets, along with its ulterior parsimonious transformation. Thus, the treatment given to the recapitulation shows appreciation for the subtle transformation, for the balance between consistency and variety.

Table 2: Villa-Lobos, SQ7, I, exposition vs. recapitulation. (author's conception).

\begin{tabular}{cccc}
\hline \hline Measures & Exposition & Measures & Recapitulation \\
\hline $1-3$ & A-Bb-C-D & $151-3$ & D-Eb-F-G \\
$4-6$ & D-Eb-F-G & $154-6$ & C-D-E-F \\
$7-9 ; 13-15$ & G-Ab-Bb-C & $159-161 ; 164-6$ & C-Db-Eb-F \\
\hline
\end{tabular}

During the exposition, the transitional area "modulates" from the diatonic first theme to the octatonic second theme. Some tonal chords, dominant-seventh like (0358), triads (3-11), and the diatonic collection (7-35), punctuates the transition, along with some melodic reiteration of the motif on tetrachord (0135). The arrival to the second theme initially passes by the octatonic septachord (7-31) before affirming the unmistakable octatonic collection (8-28).

At the recapitulation, there is an additional cardinal 7 collection (7-34), which makes more smoothly the transformation from diatonic to octatonic (Table 3). Considering the chords involved in that passage, Genus 12 (Dia-Tonal) modulates to Genus 3 (Diminished, to which octatonic belongs). A remarkable feature is the transposition pattern within the second theme, that makes the "consequent" (mm. 205-8) matches the "antecedent" (mm. 32-4) phrase of the exposition, resulting in a sort of large-scale tonal resolution.

\footnotetext{
${ }^{4}$ If one put it in simple terms, (0135) is represented by the scalar fragment C-D-E-F or G-A-B-C; both are transpositions of a tetrachord that is strongly associated with the major scale.

${ }^{5}$ Richard Parks proposes four criteria to disambiguate between Genus: 1) Prefer those genera that contain as members as many as possible (ideally, all) of the scs represented in the musical object that is the subject of investigation. [...] 2) Prefer that Genus whose primary members or characteristic members embrace the largest number of scs from the musical object. 3) Prefer that Genus which contains the smallest number of members or which contains the smallest number of primary members. 4) Prefer that Genus whose cynosural and member scs evince the greatest similarity to familiar pitch constructs [9, p. 211]. In Park's terminology, "sc" stands for "set class" to mean "pitch-class set class" (207).

${ }^{6}$ I did a detailed account on recomposition in the Seventh String Quartet (SQ7, for short) [13, pp. 446-9], after Hepokoski and Darcy's sonata theory [7, pp. 239-280].
} 


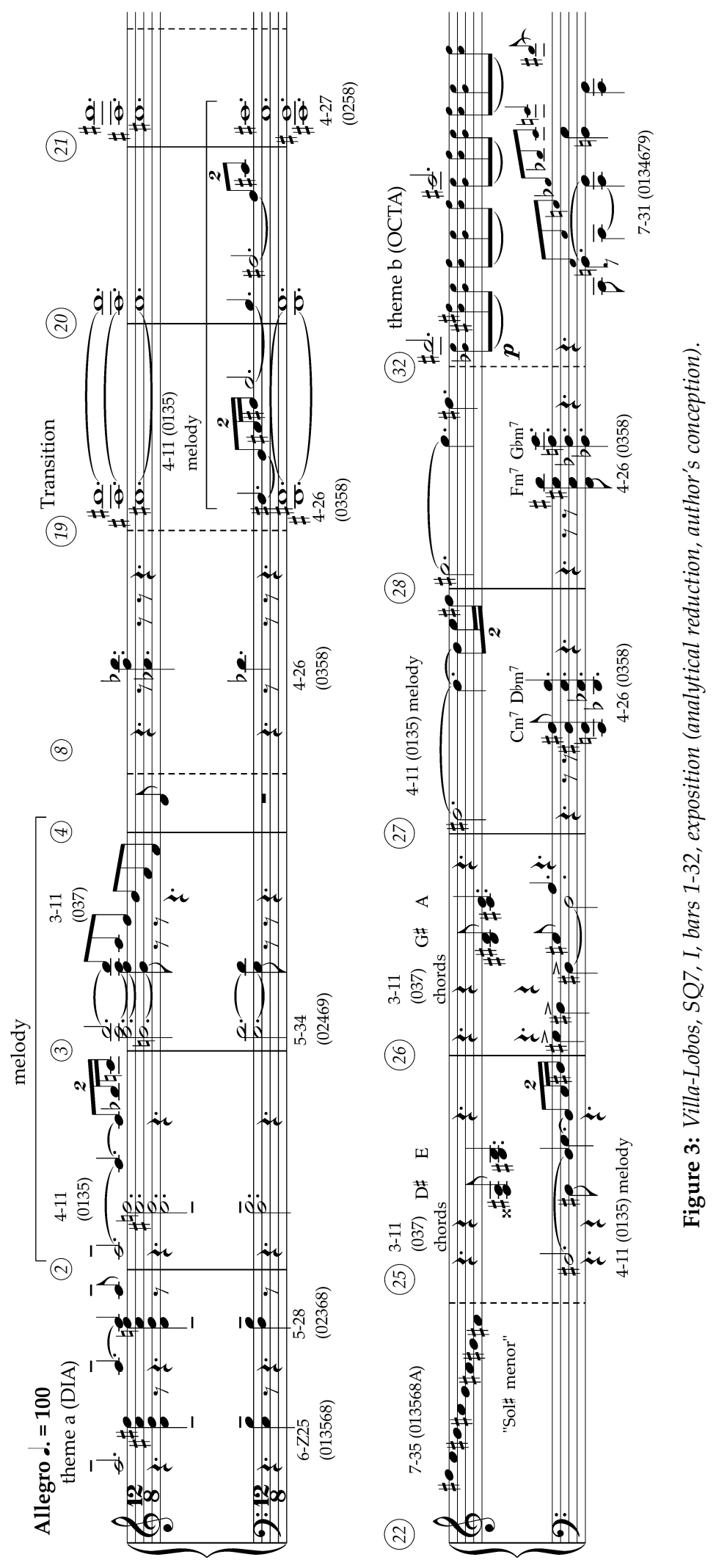


Table 3: Villa-Lobos, SQ7, I, exposition vs. recapitulation (author's conception).

\begin{tabular}{cccc}
\hline \hline $168-9$ & $176-7$ & $201-4$ & $205-8$ \\
\hline $\begin{array}{c}0,1,2,5,6,8,10] \\
(013568 \mathrm{~A})\end{array}$ & $\begin{array}{c}9,10,0,1,3,5,7] \\
(013468 \mathrm{~A})\end{array}$ & {$[5,7,8,10,11,1,2]$} & {$[0,1,2,4,6,7,9,10]$} \\
$7-35$ & $7-34$ & $(0134679)$ & $(0134679 \mathrm{~A})$ \\
& & SECOND THEME & SECOND THEME, \\
\hline TRANSITION & & & ORIGINAL PITCH \\
\hline & & Pivotal function & Genus 3 \\
& & Genus 12 $\rightarrow$ Genus 3 & (Diminished) \\
& & DIA $\rightarrow$ OCTA & OCTA \\
\hline
\end{tabular}

Drawing a tree-like graph (Figure 4) creates a 'compositional space' among the pc-sets belonging to Genus 12. It makes a path to pc-set 7-31, which acts like a pivot between Genus 12 and Genus 3, preparing the arrival to the octatonic second theme. Tetrachord (0135) is directly connected to the progenitor 3-7. Thus, the post-tonal features in Villa-Lobos's string quartet are analogous to 18th-century Classical composers like Haydn and Mozart. The chords that support the initial theme (mm. 1-2) can be understood as members of the same harmonic "family", although they cannot be assigned with triadic labels.

The second movement ("Andantino vagaroso") from Villa-Lobos's Ninth String Quartet (1945) is quite different from the SQ7. The first theme (mm. 1-12) is mostly chromatic, with a distinct expressionist color, surprisingly common in some of Villa-Lobosian music in the 1940s (Figure 5).

The melodic and harmonic layers have pc-sets belonging to Genus 1 (Atonal) (Figure 6). On the melody level, just pc-set 8-2 does not belong to that Genus, but to Supra-Genus II (gathering Genus 5 - Chroma, and Genus 6 - Semi-Chroma); even so, that is the main superset to the remaining pc-sets (Figure 7).

On the harmony side (Figure 8), voice leading is not properly parsimonious, but keeps consistent with Genus 1, except for pc-set 5-21, that belongs to Genus 4 (Augmented) and SupraGenus III (Genus 8, 9, and 10), confirming the label "atonal" (Figure 9). The inclusion related chords are displayed in normal form (Figure 10).

The thematic exposition (bars 1-30) in the first movement of Villa-Lobos's First Symphony (1916) has great harmonic diversity. The primary theme is made on the nonachord 9-4, which belongs to Genus 8 - "Atonal" and Genus 10 -- "Atonal-Tonal". That theme can be divided in three smaller units with distinct features: an almost diatonic septachord, a chromatic trichord, and a pentatonic collection (Figure 11). The sequential progression of that theme (Figure 12) results in an octatonic collection, considering their implied triadic formations (Figure 13).

Villa-Lobos does not preserve the octatonic cycle throughout the first movement. At the moment that the first theme abandons the sequential progression, its "atonal" or almost "freely tonal" profile is enhanced. No other allusion to the octatonic scale recurs during the rest of the first movement.

The transition to the subsidiary theme (mm. 13-30) shows up chords with variable density, oscillating between four and seven voices, while their cardinality bounces up and down from 4 to 6 (Figure 14).

During the transition, there is more diversity of pc-sets, according Forte's genera (Table 4). A criterion like the one developed by Parks [9] finds seven matches of pc-sets belonging to Genus 11 (Dia) and Genus 12 (Dia-Tonal). Its noteworthy to remember that the transition links to the diatonic theme B, on the Mixolydian mode, which also belongs to Genus 11 and 12 . 


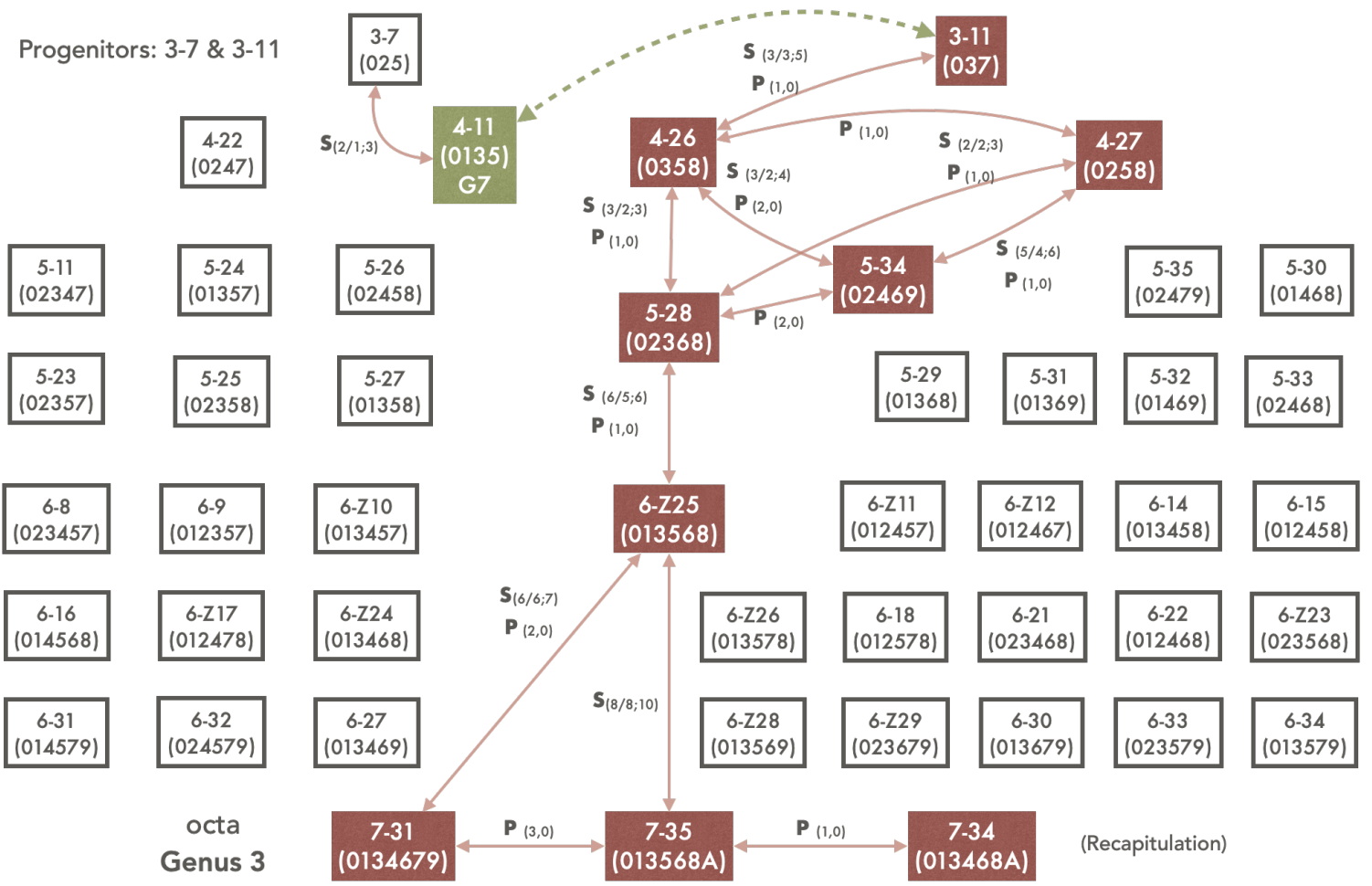

Figure 4: Villa-Lobos, SQ7, I, exposition and recapitulation, viewed from Genus 12 (author's conception).

Table 4: Villa-Lobos, Symphony n. 1, I, "Allegro moderato", mm. 13-30, genera found in the transition (author's conception).

\begin{tabular}{ccc}
\hline \hline PC sets & Amount & Genus \\
\hline $4-22$ & 3 & 11 (Dia); 12 (Dia-Tonal) \\
$5-29$ & 1 & 1 (Atonal); 3 (Diminished); 7 (Chroma-Dia) \\
& & 10 (Atonal-Tonal); 11 (Dia); 12 (Dia-Tonal) \\
$4-27$ & 2 & $2,3 \& 12$ \\
$5-35$ & 2 & $11 \& 12$ \\
$4-26$ & 1 & 12 \\
$4-z 29$ & 1 & $1 \& 2$ \\
$4-20$ & 1 & $7 \& 10$ \\
$6-32$ & 2 & $10,11 \& 12$ \\
$6-33$ & 1 & $10,11 \& 12$ \\
$3-9$ & 1 & 11 \\
$4-23$ & 1 & 11 \\
$4-19$ & 1 & $4,8,9 \& 10$ \\
\hline \hline
\end{tabular}

During the exposition, harmony can be simply described as transformational process from an "atonal" nonachord, which becomes progressively "tonal", while leading to the "diatonic" subsidiary theme (Table 5). That process is analogous to the classic modulation. 


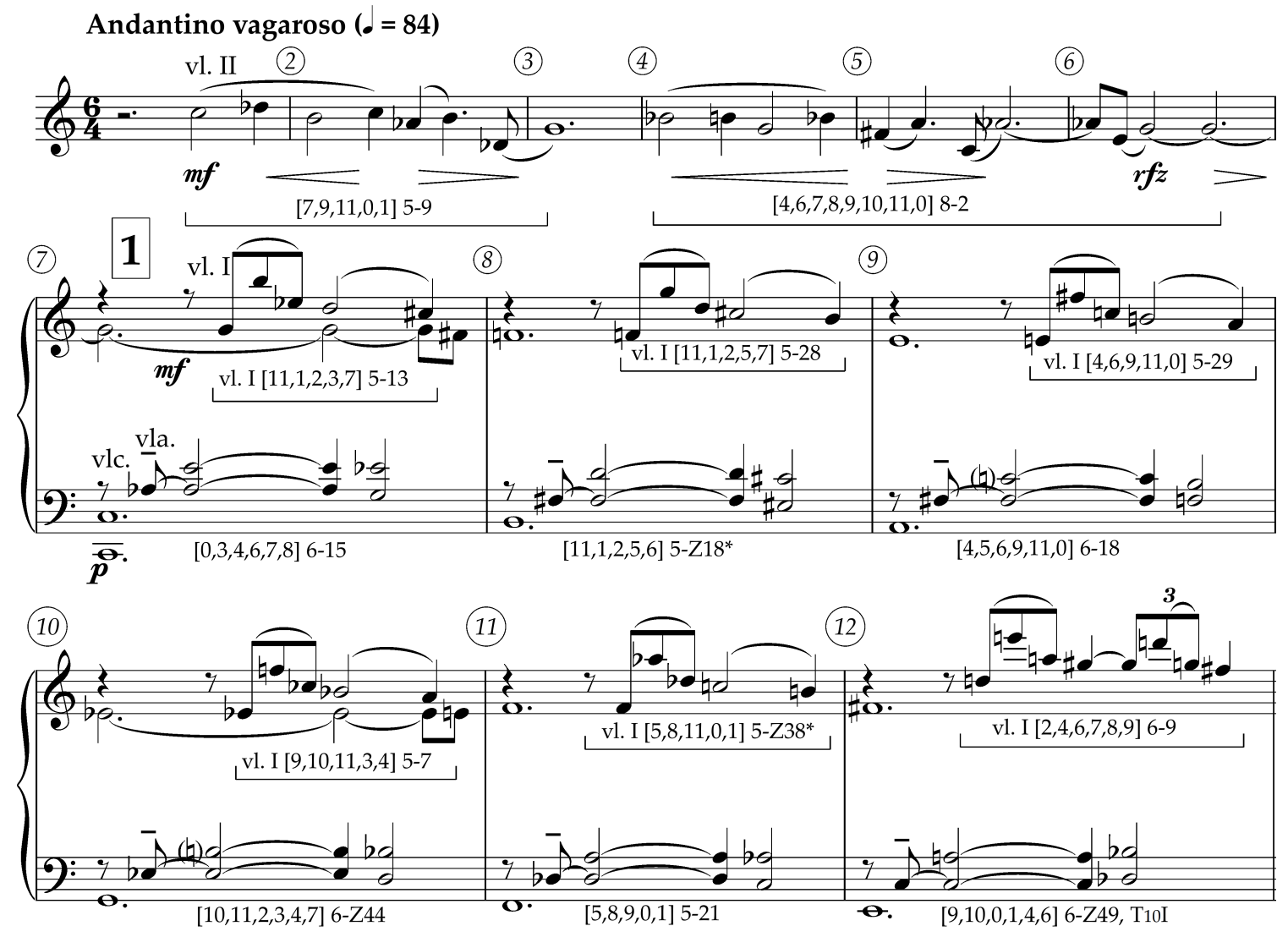

Figure 5: Villa-Lobos, SQ9, II, “Andantino vagaroso", mm. 1-12 (author's conception).

Table 5: Villa-Lobos, Symphony n. 1, I, "Allegro moderato", mm. 13-30, modulation during the transition (author's conception).

\begin{tabular}{|c|c|c|}
\hline Theme A & Transition & Theme B \\
\hline $9-4$ & \multirow[t]{2}{*}{$\rightarrow$} & $5-34 / 7-35$ \\
\hline G8; 10 & & $\mathrm{G} 2,3,12 / \mathrm{G} 11,12$ \\
\hline \multirow[t]{2}{*}{ Atonal/ Atonal-Tonal } & Dia/Dia-Tonal & $\begin{array}{c}\text { Whole-Tone, Diminished, Dia-Tonal/ } \\
\text { Dia, Dia-tonal }\end{array}$ \\
\hline & \multicolumn{2}{|c|}{ Referential collections/ Parks's Genera [10] } \\
\hline Chroma & $\rightarrow$ & Dia \\
\hline
\end{tabular}

\section{Conclusion}

Forte's theory of pc-set genera [5] offers some elements to depict the main features of the socalled harmonic "families". Notwithstanding, it has some inconsistencies and entangled details; sometimes the genera criteria fails to recognize some distinct members of the diatonic collection -even when they are quite familiar by ear; besides, it creates some non-intuitive terminology such as "Atonal-Tonal" or "Semi-Chroma" - terms whose meaning he does not clarify. In that sense, Park's theory of pc-set genera [10], [9] is more intuitively related to the musical practice. In Park's 


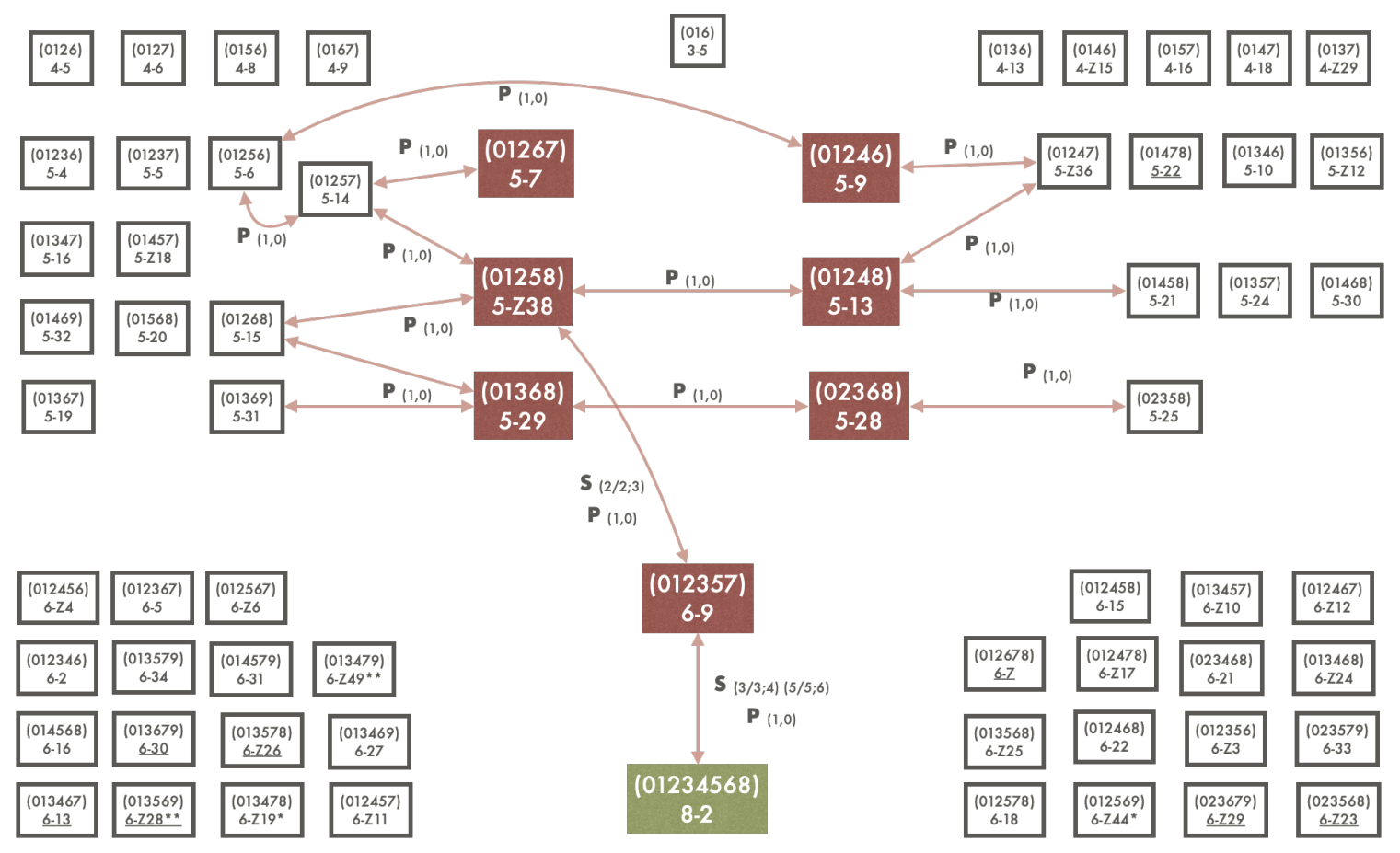

Figure 6: Villa-Lobos, SQ9, II, melody, mm. 1-12, in Genus 1 (Atonal) (author's conception).

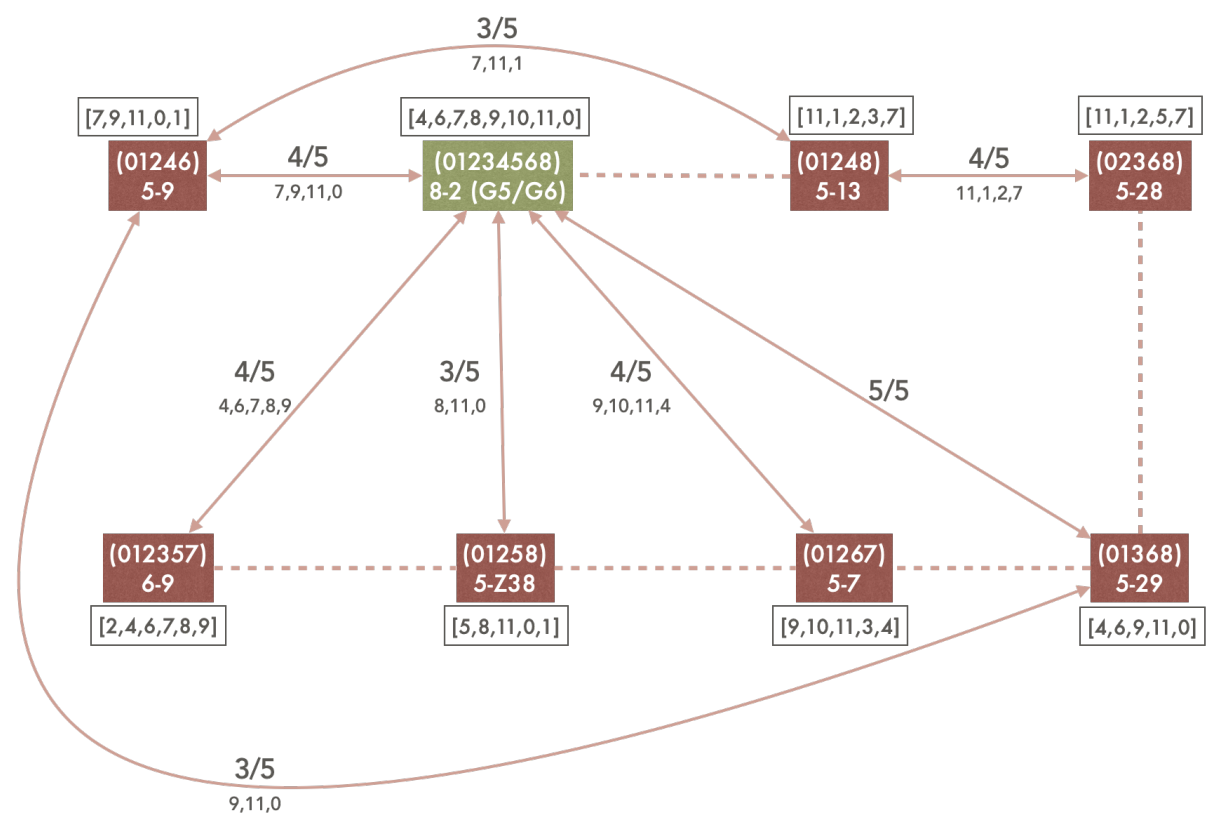

Figure 7: Villa-Lobos, SQ9, II, melody, mm. 1-12, inclusion (normal form) (author's conception). 


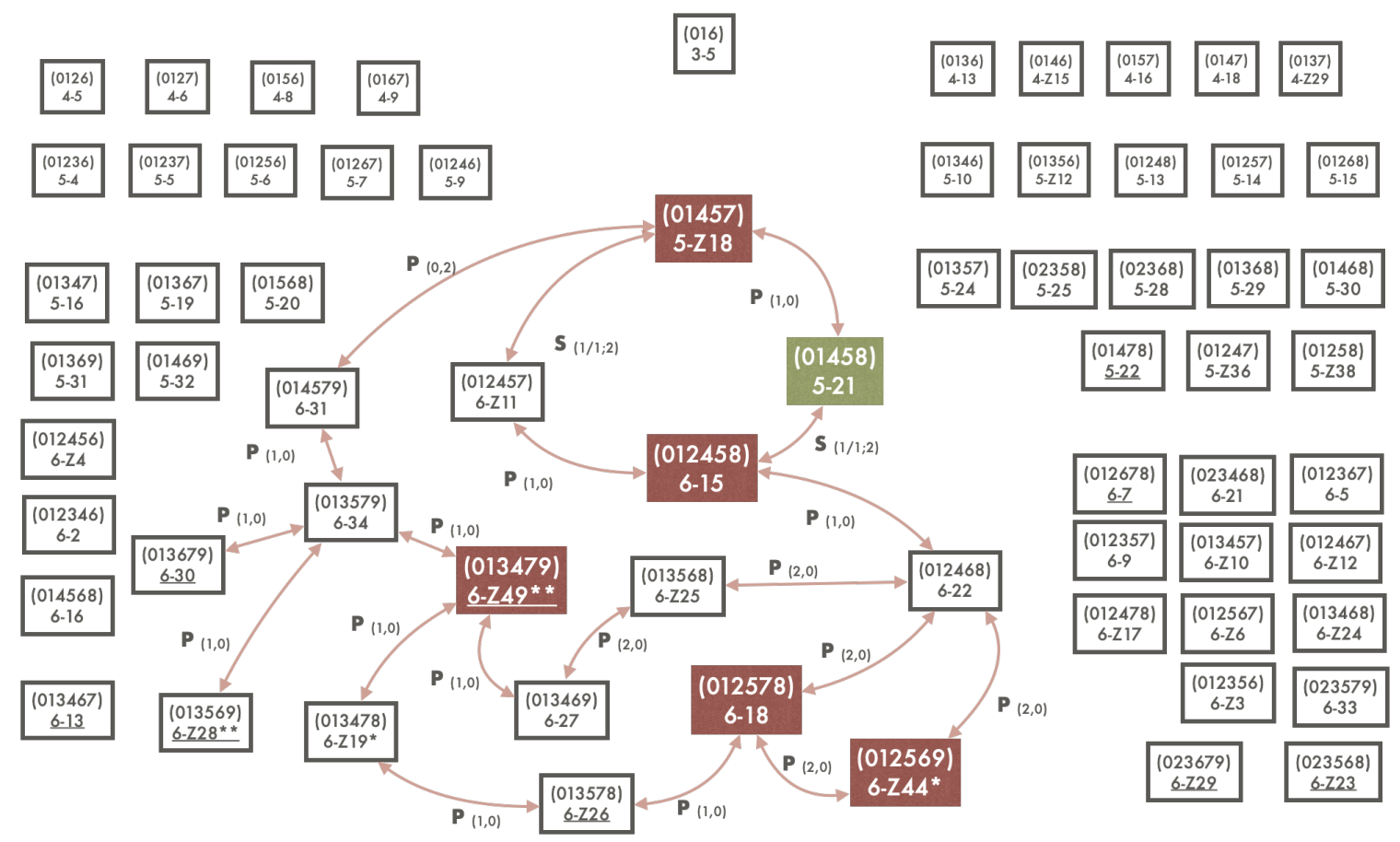

Figure 8: Villa-Lobos, SQ9, II, chords, mm. 1-12, accompaniment layer, in Genus 1 (author's conception).

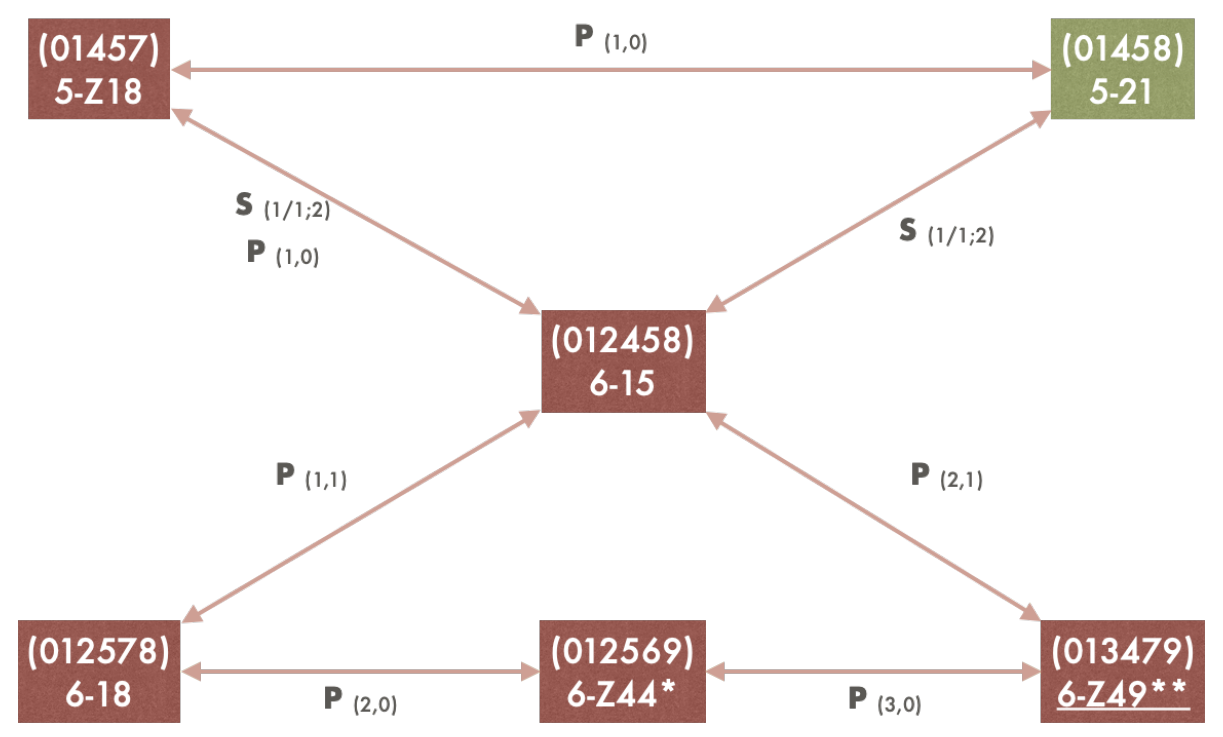

Figure 9: Villa-Lobos, SQ9, II, mm. 1-12, chords, voice leading (author's conception). 


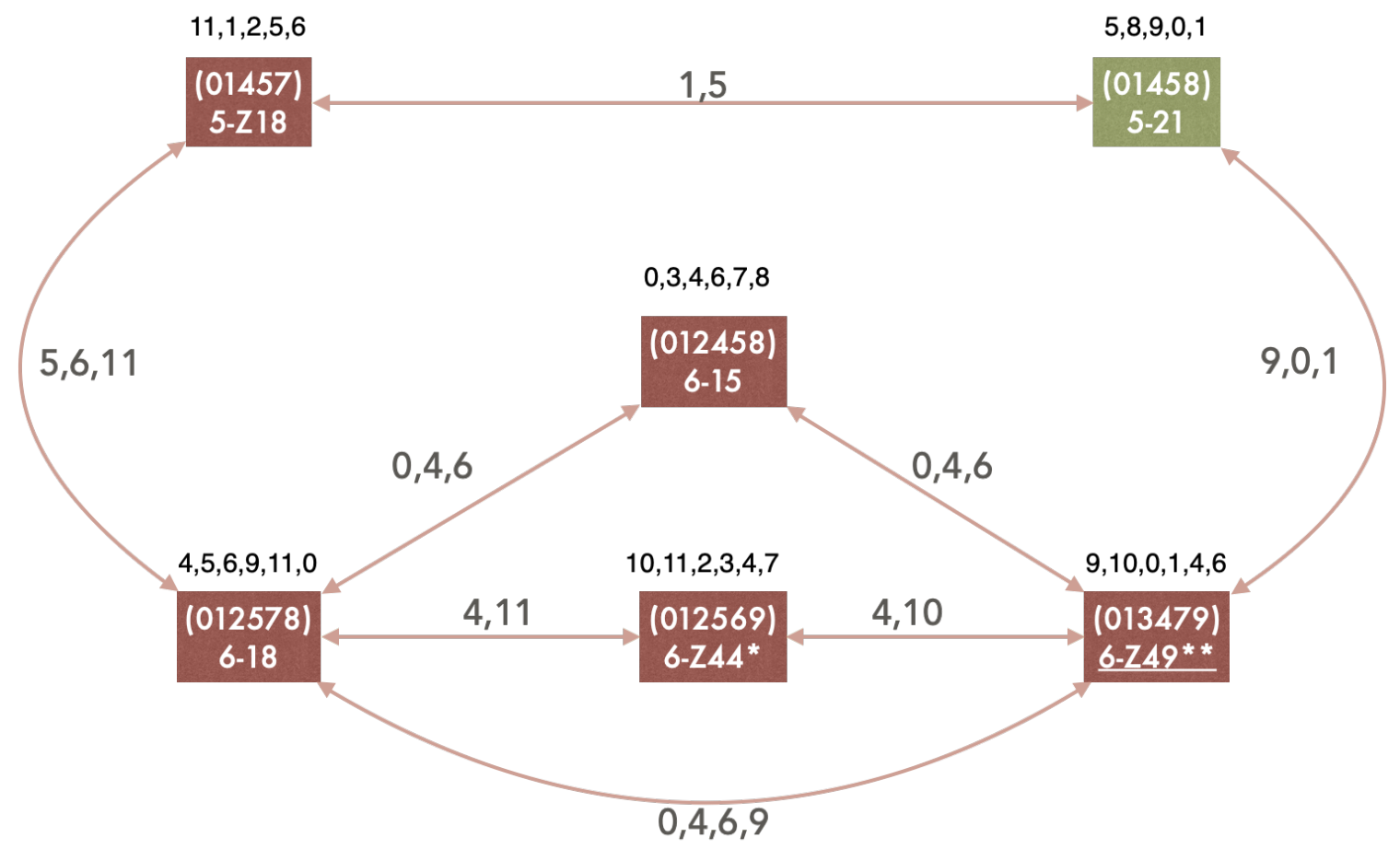

Figure 10: Villa-Lobos, SQ9, II, mm. 1-12, chords, inclusion (normal form) (author's conception).

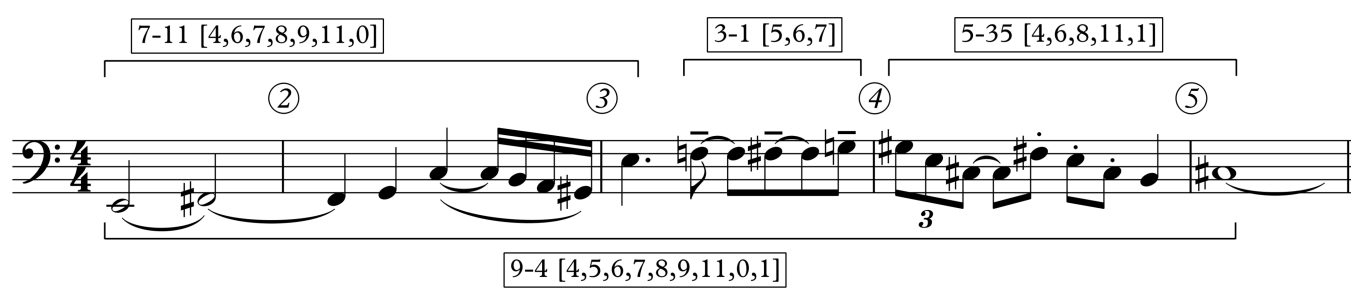

Figure 11: Villa-Lobos, Symphony n. 1, I, "Allegro moderato", mm. 1-5, primary theme (author's conception).

book on Debussy, he comes close to the concept of referential collections used frequently in more recent times [14, pp. 228-262]. However, the concept of referential collection is somewhat vague in relation to its subsets, which reinforces the value of Forte's initiative. Thus, the more the detail is sought, the more it is lost in relation to the general characteristics of the collections; on the other hand, the most comprehensive and comfortable definitions conceal the difficulty of establishing the kinship between groupings with greater precision. There is possibly a compromise between the referential option and the detailed genera option; however, I prefer to adopt a perspective that takes into account the musical context, therefore more analytical than theoretical.

The study of voice leading within these harmonic families demonstrates some important elements related to compositional processes and transformations, with a potential to enlighten some post-tonal practices. That allows us to see "genera" as "compositional spaces", where one can trace how directionality is perceived in the post-tonal repertoire. During the period of common practice, the harmonic thinking of European composers was based on the cycle of fifths, establishing the criterion of tonal distance around major and minor modes. Throughout this article, I have tried to demonstrate how Forte's genera, in association with the concept of Cohn's 

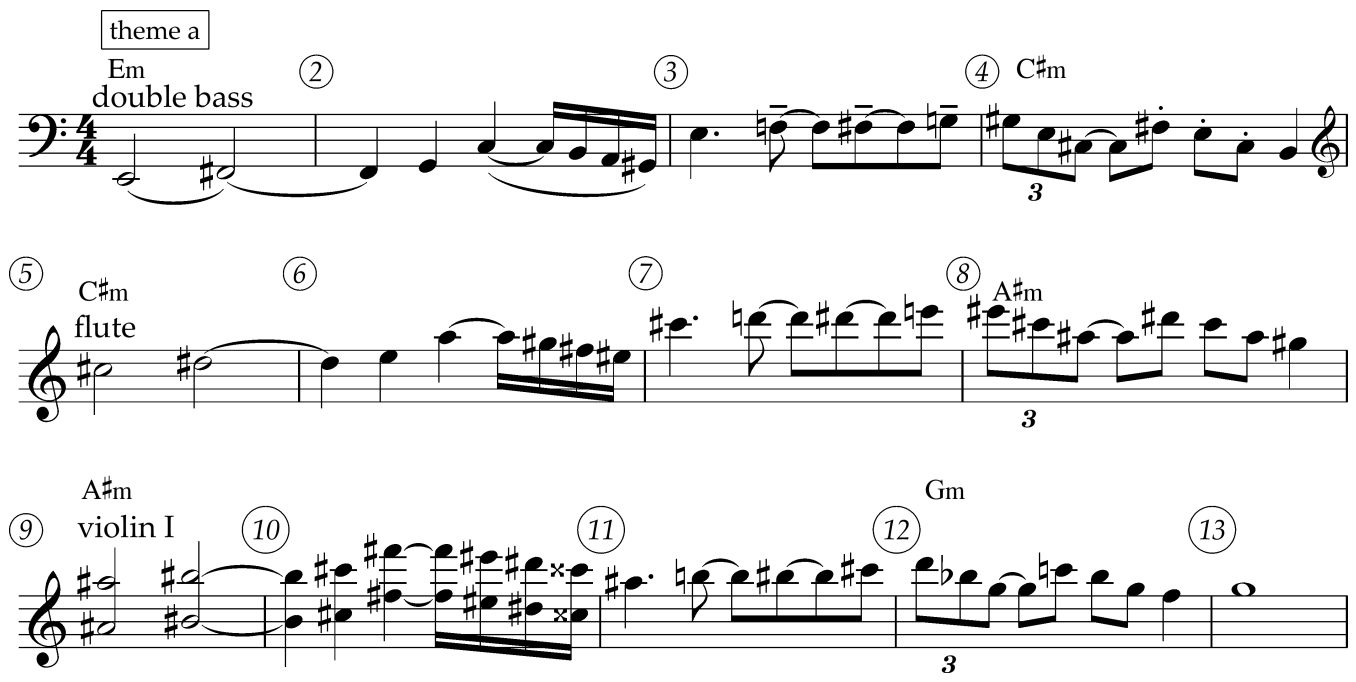

Figure 12: Villa-Lobos, Symphony n. 1, I, "Allegro moderato", mm. 1-13, sequence on theme a (author's conception).

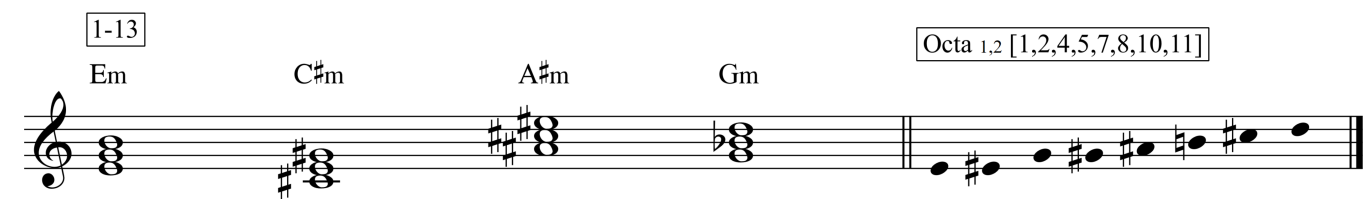

Figure 13: Villa-Lobos, Symphony n. 1, I, "Allegro moderato", mm. 1-13, first theme's implied triads and resulting octatonic collection (author's conception).
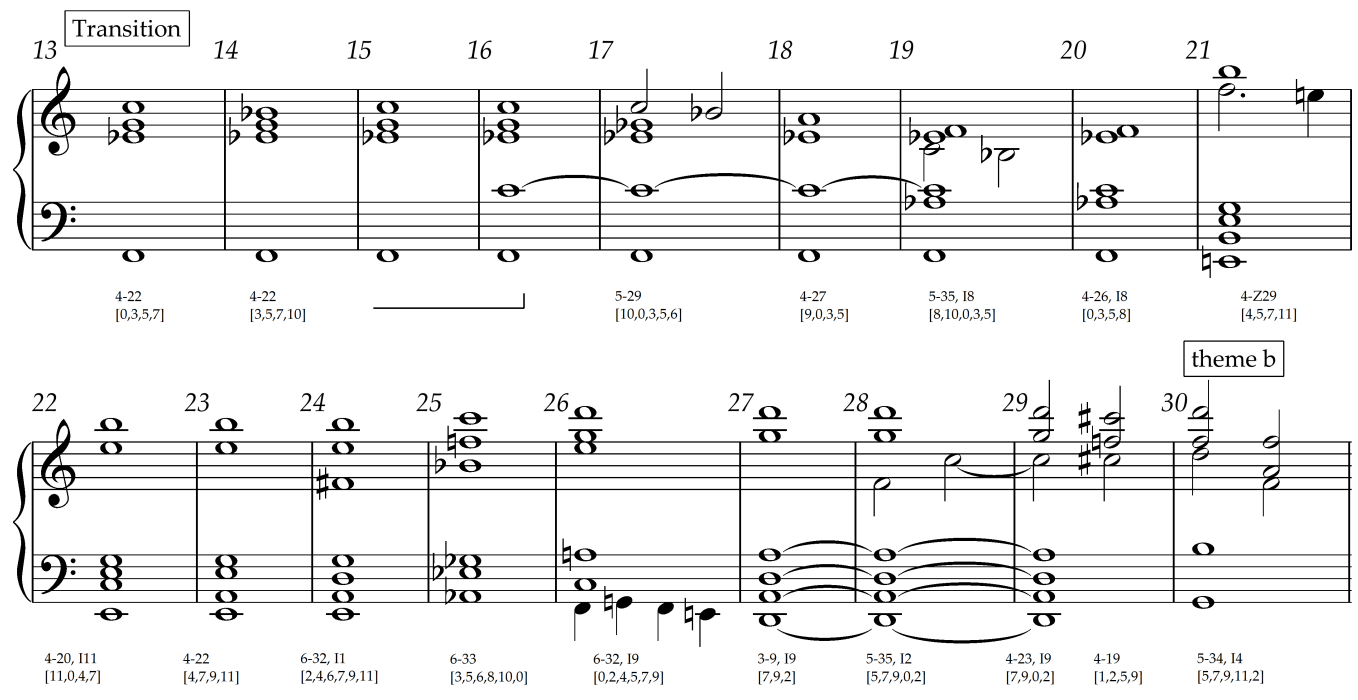

Figure 14: Villa-Lobos, Symphony n. 1, I, "Allegro moderato", mm. 13-30, transition (author's conception).

voice-leading zones, can generate an analogous mapping. In this model, changes in cardinality between pitch-class sets are incorporated into the flow within the genera, through SPLIT and FUSE operations. 
Villa-Lobos's music illustrates some post-tonal processes, in which harmonic transformation provides internal coherence; the almost complete match with Forte's genera demonstrates how selective the composer can be, tracing his harmonic paths (by ear or by calculating, it does not matter how) to be capable of finding homogeneous intervallic patterns in such expanded tonal centers, in a way pretty much analogous to the Classical tonality.

\section{REFERENCES}

[1] Callender, C. (1988) Voice-Leading Parsimony in the Music of Alexander Scriabin. Journal of Music Theory, 42/2, pp. 219-233.

[2] Coelho de Souza, R. (2018) Harmonic Perception and Voice-Leading Spaces of Set-Classes Related by Unordered Interval Classes. Musica Theorica, 3/2, pp. 46-85.

[3] Cohn, R. (2012) Audacious Euphony: Chromaticism and The Triad's Second Nature. Oxford; New York: Oxford University Press.

[4] Douthett, C.; Steinbach, P. (1988) Parsimonious Graphs: A Study in Parsimony, Contextual Transformations, and Modes of Limited Transposition. Journal of Music Theory, 42/2, pp. 241-263.

[5] Forte, A. (1988) Pitch-Class Set Genera and the Origin of Modern Harmonic Species. Journal of Music Theory, 32/2, pp. 187-270.

[6] Forte, A. (1973) The Structure of Atonal Music. New Haven: Yale University Press.

[7] Hepokoski, J.; Darcy, W. (2006) Elements of Sonata Theory: Norms, Types, and Deformations in the Late-Eighteenth-Century Sonata. Oxford: Oxford University Press.

[8] Morris, R. (1988) Voice-Leading Spaces. Music Theory Spectrum, 20/2, pp. 175-208.

[9] Parks, R. (1998) Pitch-Class Set Genera: My Theory, Forte's Theory. Music Analysis, 17/2, pp. 206-226.

[10] Parks, R. (1989) The Music of Claude Debussy. New Haven; London: Yale University Press, 1989.

[11] Peppercorn, L. (1991) Villa-Lobos, The Music: An Analysis of his Style. London; New York: Kahn \& Averill; Pro/AM Music Resources.

[12] Salles, P. (2018) Os quartetos de cordas de Villa-Lobos: forma e função. São Paulo: Edusp.

[13] Salles, P. (2017) A forma sonata nos quartetos de Villa-Lobos. In: Salles, P.; Dudeque, N. (Org.). Villa-Lobos, um compêndio: novos desafios interpretativos. Curitiba: Ed. UFPR, pp. 419-464.

[14] Straus, J. (2016) Introduction to Post-Tonal Music. New York; London: Norton.

[15] Straus, J. (2005) Voice-Leading in Set-Class Space. Journal of Music Theory, 49/1, pp. 45-108.

[16] Straus, J. (2003) Uniformity, Balance, and Smoothness in Atonal Voice Leading. Music Theory Spectrum, 25/2, pp. 305-352.

[17] Tymoczko, D. (2004) Scale Networks and Debussy. Journal of Music Theory, 48/2, pp. 219-294. 